\title{
A new development technology?
}

\section{The Rockefeller Foundation of New York is seeking new ways of adapting science to the needs of the world's poorest nations. Its problem is that technology is necessary but not sufficient for improvement.}

WHAT can science, in the hands of a private foundation, do for the huge cause of the more effective economic development of the poor countries of the world? This is the conundrum that the Rockefeller Foundation has set for itself and which, at the end of last month, it posed to a mixed group of people as if it were a question in an elegant examination paper. As with the best examination papers, there were comprehension tests as well - firsthand accounts of past successes, public health in Costa Rica, agriculture in the Punjab of India and the like - from which people were challenged to draw general conclusions.

Why the Rockefeller Foundation? The simple answer is that the foundation stands out from the general throng of private foundations by its record in this field. Dr Normal Borlaug's wheat-breeding station in Mexico, for example, was originally supported by the foundation until it became the hub of the network of international agricultural research institutes supported chiefly (but not entirely) by the World Bank. Much earlier, there had been the successful war against yellow fever, waged with Rockefeller money. Now the foundation is openly looking for similar tasks on which to spend between $\$ 50$ and $\$ 60$ million a year.

The trivial answer is even simpler. One of the foundation's more enviable assets is its delectable villa at Bellagio, the village at the tip of the peninsula separating the descenders of $\lambda$-shaped Lake Como in Northern Italy, which has been closed for the past year so that it could be made even more comfortable. Old hands now say that the new villa is distinguishable from its former self only by the absence of cracks in the plaster and the reliability of the plumbing. There is rejoicing at the reopening of the villa among those scholars who believe they may one day be able to make a case for a spell in residence, especially because there is now room for a couple of dozen of them at a time.

To the obvious jibe that such a place is too far distant in character as well as geography from the poor countries of the world to be a suitable location for a discussion of foreign aid, there is this riposte: Bellagio, strategically placed across one of the routes into Northern Europe, is surrounded by such visible evidence of Italian history, ultimately rooted in Europe's once-poor societies, that people cannot but be moved by the demonstration of the feasibility of development, slow though it may be.

The foundation's own answer to the question of why it should be engaged, the basis of its board's decision a year ago to look for new initiatives in the application of science to development, is partly that it has the experience (and the network of field officers in developing countries) and partly that the use of private funds in these connections can be "emboldening". But, properly, the foundation acknowledges that times have changed, and that the resources it can deploy are now a small fraction of those available for development from other sources. The search for distinctive initiatives may be frustrating.

As far as they go, the case-studies of past success show that science by itself is not enough. The case of Costa Rica, one of whose heroes is Leonardo Mata, the microbiologist head of the Institute for Health Research at Costa Rica's university, illustrates several points about the complexity of improvement.

Infant mortality has fallen from roughly one in five live births before 1930 to one in fifty now, to begin with only slowly as a consequence of public education (and Mata says that it helps merely to wear shoes), latterly more quickly by the control of malaria (by the 1960s), with the pursuit of the technology of oral rehydration therapy (for the prevention of infantile diarrhoea), arrangements for the collection and pooling of nursing mothers' milk and techniques of immunization.

The "silent army" of barefoot (but no doubt well-shod) doctors, originally opposed by more orthodox physicians, has done most of the field work, but the operation seems to have been helped on its way significantly by the social legislation left on the statute books by the government overthrown in the revolution of 1948. One accompaniment of this dramatic improvement in public health has been the decline of fertility (most rapidly in the late 1960s), but here again fertility rates had begun to fall, if slowly, before the technology of contraception had been made popular. Improvement is what would be called a multifactorial process, not simply a consequence of the availability of technology.

The same familiar truth emerges from the tale of India's most productive states of Punjab and Haryana, where the technology of the new high-yielding cereal varieties could be applied only after socially adventurous land reforms had been carried through. And where, as in many parts of Africa, families hold to the view that large families are intrinsically desirable, the technology of contraception may have no discernible effect on fertility, but may merely allow women to space their childrens' births conveniently.

So what new technology can be exploited? The Rockefeller Foundation is flirting with biotechnology, and not surprisingly. (Excitement that malarial vaccines are now in trials is barely supressed.) The tale at Bellagio was told by Howard A. Schneiderman of Monsanto, Charles Anzen of du Pont and Michael Sela, the immunologist past-president of the Weizmann Institute. That there will be pestresistant crop plants and novel medicines for prophylaxis and therapy is beyond dispute. The unanswered questions concern the other criteria that will have to be satisfied before their benefits can be won in developing countries.

Two sets of questions are left hanging by all discussions of this kind. To visualize the way in which novel techniques could be used is not particularly difficult. But if, for example, the innovation is a plant with artificial advantages, what arrangements will there be to ensure that the seeds will find their way into the hands of farmers now distinguished by their lack of cash with which to purchase even the essential ingredients of their craft? And if experience in Costa Rica, echoed by that elsewhere, shows that public education is the foundation of public health, is it possible to hope for much improvement generally without alleviating the lack of teachers that marks the low-income countries?

There are two lessons to be learned from discussions of this kind, both of them all too familiar. First, development must be balanced in some fashion definable only by the social context in which it happens. And the underlying economic problems of the poorest countries feed on themselves. This does not mean that development is not possible but merely that it depends as much on good luck and imagination as on technology.

This contradiction is why the optimists talk of the chance that the rules may change, perhaps by the new agreement on trade two or three years from now. The other side of the coin is the waywardness of the governments whose people are the most in need of help. Technology is at least neutral.
John Maddox 